\section{References}

${ }^{1}$ Anonymous. Cells, ions, and blood-pressure [Editorial]. Lancet 1982 ;ii 965-7.

2 Orlov SN, Postnov YV. $\mathrm{Ca}^{2+}$ binding and membrane fluidity in essential and renal hypertension. Clin $S_{c i} 1982 ; 63: 218-24$

3 Jones AW. Altered ion transport in large and small arteries from spontaneously hypertensive rats and the influence of calcium. Circ Res $1974 ; 34$, suppl $1: 117-22$.

4 Heagerty AM, Milner M, Bing RF, Thurston H, Swales JD. Leucocyte membrane sodium transport in normotensive populations: dissociation of abnormalities of sodium efflux from raised blood pressure. Lancet 1982 ;ii :894-6.

${ }^{5}$ Blaustein MP. Sodium ions, calcium ions, blood pressure regulation and hypertension: a reassessment and a hypothesis. Am 7 Physiol 1977; 232:C165-73.

- Anonymous. Calcium antagonists in hypertension [Editorial]. Lancet $1982 ;$ ii :307-8.
7 Edmondson RPS, Thomas RD, Hilton PJ, Patrick J, Jones NF. Abnormal leucocyte composition and sodium transport in essential hypertension. Lancet 1975 ; : $1003-5$.

8 Braunwald E. Mechanism of action of calcium-channel-blocking agents. $N$ Engl ₹ Med 1982;307:1618-27.

9 Motulsky HJ, Snavely MD, Hughes RJ, Insel PA. Interaction of verapamil and the other calcium channel blockers with $a_{1}$ and $a_{2}$ adrenergic receptors. Circ Res 1983;52:226-31.

10 Robinson BF, Dobbs RJ, Bayley S. Response of forearm resistance vessels to verapamil and sodium nitroprusside in normotensive and hypertensive men: evidence for a functional abnormality of vascular smooth muscle in primary hypertension. Clin Sci 1982;63:33-42.

11 De Wardener HE, MacGregor GA. The natriuretic hormone and essential hypertension. Lancet 1982 ;ii:1450-3.

12 Rothstein A. Membrane phenomena. Ann Rev Physiol 1968;30:15-22.

13 Swales JD. Ion transport in hypertension. Biosc Rep $1982 ; 2: 967-90$.

(Accepted 18 August 1983)

\title{
Changes in gastric mucosa after vagotomy and gastrojejunostomy for duodenal ulcer
}

\author{
P C H WATT，J M SLOAN， T L KENNEDY
}

\begin{abstract}
Gastric mucosa was studied histologically in 141 patients. Eighty two had undergone vagotomy and gastrojejunostomy between 15 and 25 years previously for duodenal ulcer, and 59 control patients had a long history (minimum 15 years) of duodenal ulcer treated medically. No carcinoma was found in either group. Two patients with severe dysplasia and 13 patients with moderate dysplasia were found in the study group, compared with none in the control group $(p<0.01)$. Intestinal metaplasia was seen in $44(53 \%)$ of the study group and $16(27 \%)$ of the control group $(p<0.01)$. Atrophy and gastritis were more severe $(p<0.01$ for atrophy; $p=0.05$ for gastritis) in the study group.

Gastric mucosal changes were more severe after surgical treatment for duodenal ulcer than after medical treatment, and possibly a high incidence of gastric carcinoma may occur 25 years after vagotomy and gastrojejunostomy.
\end{abstract}

\section{Introduction}

The poor prognosis associated with cancer of the stomach diagnosed at a late stage has led to a search for high risk groups of patients with the idea that screening by endoscopy and biopsy might lead to a higher yield of early gastric cancers. Patients with lesions thought to be premalignant could then be followed up with greater care. One such high risk group consists of patients many years after surgery for benign peptic ulcer. Several endoscopic studies have disclosed a high incidence of premalignant and malignant changes in the stomach many

Royal Victoria Hospital and Queen's University, Belfast P C H WATT, MB, FRCs, research fellow, department of surgery J M SLOAN, MD, MRCPATH, consultant pathologist

T L KENNEDY, $\mathrm{MCH}$, FRCS, consultant surgeon

Correspondence to: Mr P C H Watt, Department of Surgery, Institute of Clinical Science, Grosvenor Road, Belfast BT12 6BJ. years after operation. ${ }^{1-3}$ These data are difficult to interpret if no comparison is made with the incidence of the same histological changes in patients of similar age and geographic location who have not had surgery. As gastric ulcer itself may occasionally lead to gastric cancer ${ }^{4}$ it is not clear whether the changes occurring in the stomach after operation are the result of the operation or of the underlying ulcer disease. One study reported a lower incidence of gastric cancer in patients after gastrectomy at least in the early years and suggested that this may have been due to the antral resection, which reduces the area of gastric mucosa at risk and therefore reduces the incidence of malignant change. ${ }^{5}$ This suggests that non-resection operations such as vagotomy and drainage should also be considered.

In this study the only operation that we investigated was vagotomy and gastrojejunostomy, which had been done for duodenal ulcer in all cases. We compared the mucosal findings in this group with the mucosal findings in a control group of patients with duodenal ulcer who had received only medical treatment.

\section{Patients and methods}

The study group consisted of 82 patients (64 men, 18 women), al of whom had undergone vagotomy and gastrojejunostomy between 1957 and 1967 in the Royal Victoria Hospital, Belfast. The mean age was $60(\mathrm{SD} 10 \cdot 1)$ years and the mean time since surgery $21(3 \cdot 9)$ years. The patients' hospital notes were examined and present addresses obtained from their current general practitioners. Patients were contacted and interviewed, a symptom questionnaire was filled out, and each patient was offered endoscopy. Patients were excluded if they had been born before 1900, if they had had any subsequent gastric surgery, if they were taking any drug known by us to affect the gastric mucosa, or if at the time of endoscopy they had any raised or ulcerated mucosal lesion in the stomach, jejunum, or duodenum. Seven biopsy specimens were obtained from each patient. Five were taken from the peristomal area, up to $4 \mathrm{~cm}$ from the stoma rather than from the exact edge. Two were taken from the body of the stomach.

The control group consisted of 59 patients ( 46 men, 13 women) whose mean age was $61(9 \cdot 7)$ years. All had a long history of duodenal ulcer treated only by medical means and diagnosed at some stage by barium meal examination (47), past endoscopy (seven), or duodenal scanning on current endoscopy (five). The exact duration of the 
symptoms of the ulcer in this group was often difficult to ascertain, but patients were excluded if they could not definitely admit to recurrent symptoms of more than 15 years' duration. Patients were also excluded if they were under 40 years old, if they were taking drugs known by us to affect the gastric mucosa, or if they had active duodenal ulceration or any raised or ulcerated lesion in the stomach or duodenum. Five biopsy specimens were taken from the area within $4 \mathrm{~cm}$ of the pylorus and two from the body of the stomach.

Endoscopy was carried out using an Olympus GIF Q or P gastroscope. Intravenous diazepam was used for sedation, and the pharynx was sprayed with xylocaine. Ethical committee approval was obtained for the study.

The biopsy specimens were collected in formalin, fixed in mercuric formol, embedded in wax, and stained with haematoxylin and eosin. They were assessed without knowledge of the group to which the patient belonged. Each specimen was assessed for dysplasia, intestinal metaplasia, atrophy, and gastritis.

Dysplasia-The criteria of Morson et $a l^{6}$ were used to classify each biopsy specimen as showing no dysplasia or mild, moderate, or severe dysplasia.

Intestinal metaplasia-A scoring system of 0-6 was used to indicate the amount of intestinal metaplasia in each specimen. To aid reproducibility of assessment standard photographs were taken of specimens illustrating scores of 1,3 , and 5 . All other specimens were scored by comparison with these standards. A score of 1 indicated that one or two gastric pits were affected; 3 that about half the pits were affected; and 5 that nearly all the pits were affected.

Atrophy-A similar scoring system of 0-6 was used, constant comparison being made with standard photographs of specimens illustrating scores of 1,3 , and 5 . A score of 1 indicated minimal loss of specialised glands; of 3 that about half the glands were missing; and of 5 that nearly all specialised glands were missing. Separate standard photographs were used for body and antral mucosa.

Gastritis-Again a score of $0-6$ was used, which depended on the quantity of inflammatory cells in the lamina propria. Standard photographs of specimens illustrating scores of 1,3 , and 5 were used for comparison. Score 1 indicated a minimal infiltrate of inflammatory cells in the superficial layer of the lamina propria (equivalent to mild chronic superficial gastritis); 3 indicated a heavy infiltrate of chronic inflammatory cells spread throughout the lamina propria. Most of these specimens showed some degree of atrophy, and therefore a score of 3 was roughly equivalent to chronic atrophic gastritis. Score 5 indicated a heavy infiltrate of acute as well as chronic inflammatory cells. These specimens also often showed large numbers of intraepithelial neutrophils and considerable epithelial regenerative change. This would correspond to active chronic superficial gastritis or active chronic atrophic gastritis depending on the degree of atrophy.

\section{Results}

Three patients in the study group had symptoms of the dumping syndrome, three had symptoms of mild bile reflux, four had symptoms of oesophagitis, and six had diarrhoea. The rest (66) were asymptomatic. Most of the control group (52) were undergoing endoscopy because of recurrent mild dyspepsia. Seven underwent endoscopy for investigation of anaemia.

One way analysis of variance showed no significant difference in age distribution between the study and control groups.

\section{ENDOSCOPIC FINDINGS}

Out of all the patients in the study group who underwent endoscopy, two were excluded on the basis of stomal ulcer and seven on the basis of raised plaques or polyps in the vicinity of the stoma or antrum. None of these lesions was malignant. Of the 82 patients who entered the study group, several showed abnormal coloration of all or part of the mucosa. White areas (usually about $1-2 \mathrm{~cm}$ across) were found close to the stoma in 18 patients. On biopsy these invariably showed considerable intestinal metaplasia with associated atrophy. In one patient the gastric antrum was almost entirely white, and this patient had gross widespread intestinal metaplasia and atrophy. In 33 patients the gastric mucosa was considered subjectively by one observer to be appreciably redder than normal.

Of the 59 control patients, 36 had duodenal scarring. White areas around the pylorus were seen in five, although none of these was as pronounced as the similar stomal lesions in the study group. Sixteen patients subjectively had a red antral mucosa.

\section{MICROSCOPIC FINDINGS}

Dysplasia-Table I shows the numbers of patients in each group for whom one or more of the biopsy specimens showed dysplastic $\widehat{C}$ changes. The two patients who had severe dysplasia both showed the lesion in two specimens from the peristomal region. Of the 13 patients with moderate dysplasia, three showed the lesion in peristomal specimens and specimens from the body of the stomach. One of these three showed the change in five specimens, one in four specimens, 0 and one in two specimens. In 10 patients moderate dysplasia was confined to the peristomal biopsy specimens. The change was seen $\overrightarrow{\vec{F}}$ in five specimens in one patient, three specimens in one patient, two specimens in five patients, and one specimen in three patients. The number of patients with moderate or severe dysplasia in the study $\frac{\bar{F}}{\bar{N}}$ group (15 out of 82 ) was significantly greater than that in the control $\frac{5}{7}$ group (none) $\left(p<0.01, \chi^{2}\right.$ test). There was no significant difference $\stackrel{\mathbb{Q}}{\Omega}$ between the two groups for mild dysplasia.

Intestinal metaplasia-Evidence of intestinal metaplasia was seen in at least one biopsy specimen in $44(53 \%)$ patients in the study $\vec{\circ}$ group and in $16(27 \%)$ patients in the control group. This difference $\overrightarrow{-}$ was significant $\left(p<0.01, \chi^{2}\right.$ test $)$. Widespread intestinal metaplasia $\vec{\omega}$ was arbitrarily defined as a score of 5 or more when the scores for all specimens in any one patient were added together. Fourteen of the 3 study group had widespread intestinal metaplasia compared with only three of the control group. In all the control patients with $\infty$ intestinal metaplasia the change was seen in the peripyloric specimens; o in addition the change was seen in specimens from the body of the $f$ stomach in three patients. Among the $\mathbf{4 4}$ patients in the study group $\omega$ with intestinal metaplasia the change was seen in only the peristomal $\vec{A}$ specimens in 32, in only the specimens from the body of the stomach in seven, and in both areas in five.

Atrophy-The mean score for atrophy in the five peristomal or $\frac{\text { ? }}{2}$ peripyloric biopsy specimens and in the two specimens taken from $\vec{N}$ the body of the stomach was calculated for each patient. In addition, $Z$ a mean score for all seven specimens was calculated for each patient. Table II shows the means of these scores in each patient group. The Mann Whitney $U$ test showed that the study group had significantly more atrophy than the control group in peristomal specimens $(\mathrm{p}<0.01)$, Ф specimens in 32 , in only the specimens from the body of the stomach $\vec{\oplus}$ $(\mathrm{p}<0.01)$.

Gastritis-An overall gastritis score and a score for each site were $\omega$ calculated for each patient as for atrophy. Table II shows the average scores in the study and control groups. The Mann Whitney U test showed no significant difference in gastritis scores between the peristomal biopsy specimens in the study group and the peripyloric specimens in the control group. The gastritis scores for specimens $\frac{O}{\mathbb{Q}}$ taken from the body of the stomach, however, were significantly $\varrho$ greater in the study group $(\mathrm{p}=0.01)$ than the control group. When $\overrightarrow{\overrightarrow{0}}$ all the specimens were considered the score was higher in the study 3 group $(\mathrm{p}=0.05)$. Thirteen patients $(16 \%)$ in the study group and seven controls $(12 \%)$ had a gastritis score of 4 or more in one or more specimens (that is, an appreciable infiltrate of acute as well as chronic inflammatory cells).

TABLE I-Classification of dysplasia according to most severe dysplasia found in any biopsy specimen (figures are numbers $(\%)$ of patients)

\begin{tabular}{|c|c|c|c|}
\hline & Study group & Controls & Significance \\
\hline $\begin{array}{l}\text { No dysplasia } \\
\text { Mild dysplasia } \\
\text { Moderate dysplasia } \\
\text { Severe dysplasia } \\
\text { Carcinoma }\end{array}$ & $\begin{array}{l}52(63 \cdot 0) \\
15(18 \cdot 2) \\
13(15 \cdot 8) \\
2(2 \cdot 3) \\
0\end{array}$ & $\begin{array}{l}\left.\begin{array}{l}54(91 \cdot 0) \\
5 \\
0 \\
0 \\
0\end{array}\right\} \\
(8 \cdot 0)\end{array}$ & $\begin{array}{c}\text { NS } \\
\mathrm{p}<0.01\end{array}$ \\
\hline Total & 82 & 59 & \\
\hline
\end{tabular}

TABLE II-Mean (SD) scores for atrophy and gastritis for all patients in each group

\begin{tabular}{|c|c|c|c|}
\hline & Study group & Controls & Significance \\
\hline & \multicolumn{2}{|c|}{ Muscosal atrophy } & \multirow{4}{*}{$\begin{array}{ll}p & 0.01 \\
p & 0.01 \\
p & 0.01\end{array}$} \\
\hline $\begin{array}{l}\text { specimens } \\
\text { s }\end{array}$ & $1.8(1 \cdot 0)$ & $0.8(0.8)$ & \\
\hline Gastric body specimens & $1 \cdot 0(1 \cdot 1)$ & $0.4(0.6)$ & \\
\hline All specimens & $1.5(0.8)$ & $0.6(0 \cdot 7)$ & \\
\hline \multicolumn{4}{|c|}{ Gastritis } \\
\hline $\begin{array}{l}\text { Peristomal or peripyloric } \\
\text { specimens }\end{array}$ & $2 \cdot 1(0 \cdot 7)$ & $1.8(0 \cdot 8)$ & NS \\
\hline Gastric body specimens & $1.6(0.7)$ & $1.09(0.8)$ & $p=0.01$ \\
\hline All specimens & $1.9(0.65)$ & $1.6(0 \cdot 7)$ & $p=0.05$ \\
\hline
\end{tabular}


Reproducibility - To assess the reproducibility of our method of scoring the specimens 40 specimens were assessed blindly a second time and the correlation between the first and second assessments calculated using Kendall's correlation coefficient. This test showed a highly significant correlation between first and second assessments for all four variables ( $p<0.0001$ in each case).

\section{Discussion}

The predisposition of the stomach after operation to malignant and premalignant change remains controversial. Several studies have shown an increased incidence of carcinoma after gastric surgery by investigating either post mortem ${ }^{7}$ or at endoscopy the number of stomach cancers in patients who have undergone gastric surgery. Schrumpf et al, using endoscopy, found four cases of infiltrating carcinoma in 108 patients after gastrectomy, which is more than they would have expected in the normal population. Stalsberg and Taksdal studied patients with gastric cancer at postmortem examination. ${ }^{8}$ The incidence of previous gastric surgery was greater in patients with gastric cancer than in controls if the surgery had been carried out 25 or more years before. McLean Ross et al, who studied the cause of death in a large group of patients after gastric surgery (mainly gastrectomy), found a slightly reduced incidence of gastric carcinoma, although the average time from gastrectomy to death was only 18.9 years. ${ }^{9}$ This study and that of Welvaart and Warnsinck, ${ }^{5}$ which also showed a reduced death rate from gastric cancer, appear to have relied on causes of death unconfirmed by postmortem examination. On balance, we interpret current reports as indicating an increased incidence of gastric carcinoma 25 years after gastrectomy.

Our study group consisted entirely of patients who had undergone vagotomy and gastrojejunostomy. The antrum is intact in these patients and therefore possibly exposed to the same carcinogenic factors as stomachs after gastrectomy, which suggests the possibility that these patients might have a higher risk of malignant and premalignant change than patients who have undergone gastrectomy. The fact that we studied patients with duodenal and not gastric ulcers and that we incorporated a control group of patients with duodenal ulcers treated medically reduces the possibility of any histological abnormality being due to progression of the underlying disease.

The control group used in this study was not ideal. The best form of control would have been to randomise all the patients with duodenal ulcer into operative and non-operative groups and to study them prospectively by endoscopy over a prolonged period. This could not be considered on an ethical basis. Our control group might be criticised on the basis that as they did not receive surgical treatment the duodenal ulcers may not, on average, have been as severe as those in the study group. We believe, however, that our control group was the best feasible, and every effort was made to use patients of similar age and for whom the time of onset of symptoms had been similar to that in the study group. A control group of normal people would be ethically and also scientifically undesirable as they would be different from the study group in two respectsnamely, the absence of duodenal ulceration and of surgerywhereas our controls were different only in respect of surgery.

In the study group biopsy specimens were taken mainly in the peristomal region as most cancers after gastric surgery have been found to originate in this region. ${ }^{710}$ Such specimens would be expected to show the highest yield of malignant or premalignant change. Specimens were not taken at the precise junction of gastric and jejunal mucosa as many specimens taken there consist of only jejunal mucosa.

So that our control group would be valid we used equivalent sites of biopsy in these patients. We chose the area up to $4 \mathrm{~cm}$ from the pylorus on the basis that this area is the same distance from any carcinogenic factor refluxing into the stomach as the area up to $4 \mathrm{~cm}$ from the stoma in the study group, although presumably the refluxed material would have reached a more extensive area in the study group than in the control group. As the antrum has the highest incidence of gastric cancer in the anatomically normal stomach ${ }^{11}$ and the peristomal area the highest incidence in the postoperative stomach the two areas are probably equivalent on the basis of "areas of highest expected abnormality."

The value of taking multiple biopsy specimens is emphasised by the fact that three patients showed evidence of moderate dysplasia in only one specimen. When reviewing patients with moderate and severe dysplasia it may be necessary to examine more specimens per patient than the seven used in this study. Obviously, if endoscopy of the stomach after operation is to become routine the number of specimens to be taken must be practical for a busy endoscopy and pathology department. In future we intend to take about 12 per patient.

The incidence of dysplasia found in this study is difficult to compare with that found in other studies. Ferrands et al found 11 cases of dysplasia in 71 patients, but they used several types of operation and studied patients with both duodenal and gastric ulcers. ${ }^{12}$ In addition, as the histological assessment is essentially subjective, observed difference is important. As the same criteria were used in each group, however, we can state that the incidence of moderate to severe dysplasia is greater in patients with duodenal ulcer treated surgically rather than medically. As we did not find carcinoma in either group the importance of our findings on dysplasia remains in doubt. It is widely agreed, however, that gastric dysplasia must be treated with caution. ${ }^{6}{ }^{13}$

Morson suggested that intestinal metaplasia is associated with gastric cancer. ${ }^{14}$ Intestinal metaplasia has been found in higher incidence in populations at high risk of gastric cancer than in populations of low risk. ${ }^{15}$ As the incidence is high in normal (especially elderly) populations its importance for each individual patient is small. Some authors have suggested that it may be used as an epidemiological marker of the incidence of gastric cancer in a population. ${ }^{16}$ As we found a higher incidence of intestinal metaplasia in the study group than the controls it might be extrapolated that the study group may have constituted a population with a high risk of developing gastric cancer.

In this study we assessed gastritis and atrophy separately. We thought that this gave a more valid comparison between groups than the conventional diagnoses of chronic atrophic gastritis and chronic superficial gastritis, which we found difficult to assess quantitatively and reproducibly. The degree of atrophy in specimens from both peristomal sites and the body of the stomach was greater in the study group. Siurala et al showed an increased incidence of gastric carcinoma on follow up of a group of patients with atrophic gastritis. ${ }^{17}$

Patients with duodenal ulcer often have associated antral gastritis, ${ }^{18}$ and the present study supports this. Hence it is not surprising that the peristomal biopsy specimens in the study group did not show a significant increase in gastritis over the peripyloric specimens in the control group. Most of the peripyloric specimens and the peristomal specimens were of antral type mucosa. It appears that the construction of a gastrojejunostomy does not have any great effect on the already existing antral gastritis in patients with duodenal ulcer. The amount of gastritis in the rest of the stomach, however, is increased.

The aetiology of premalignant and malignant change in the stomach after operation is the subject of controversy. The rise of $\mathrm{pH}$ in the stomach may lead to bacterial metabolism of bile to secondary and unconjugated bile acids, which may be carcinogenic in the long term. ${ }^{19}$ An alternative theory suggests that the postoperative rise in $\mathrm{pH}$ leads to bacterial formation of N-nitroso compounds, and one study showed increasing concentrations of $\mathrm{N}$-nitroso compounds with increasing $\mathrm{pH}$ in human gastric juice, ${ }^{20}$ although a more recent study did not confirm this. ${ }^{21}$

Our findings of a high incidence of dysplasia yet no case of infiltrating carcinoma in patients who had undergone vagotomy 
and gastrojejunostomy makes it difficult for us to suggest a policy of follow up for these patients in general. We intend to perform endoscopy about every six months in patients with severe dysplasia and every year in those with moderate dysplasia. We are not convinced of the value of frequent endoscopic follow up in those of our patients in whom we found other histological abnormalities. Even though we found no case of infiltrating carcinoma, the high incidence of dysplasia in our patients is disturbing, especially in view of the fact that the average time of our follow up was only 21 years. We fear that a high incidence of gastric carcinoma may emerge 25 years after patients have undergone vagotomy and gastroenterostomy.

PCHW was in receipt of a Royal Victoria Hospital fellowship throughout the study. Mr C C Patterson, department of medical statistics, Queen's University, Belfast, advised on statistical analysis. Mr J Reid and staff of the histopathology laboratory, department of pathology, Royal Victoria Hospital, made all the microscopic slides. We thank Smith, Kline and French Research Ltd and the Mater Infirmorum Hospital gifts and endowment fund for financial support.

\section{References}

${ }^{1}$ Schrumpf E, Serck-Hanssen A, Stadaas J, Aune S, Myren O, Osnes M. Changes in the gastric stump, 20-25 years after partial gastrectomy. Lancet 1977 ;ii:467-9.

${ }^{2}$ Domellof L, Eriksson S, Janunger K-G. Late precancerous changes and carcinoma of the gastric stump after Billroth I resection. Am $\mathcal{F}$ Surg 1976;132:26-31.

${ }^{3}$ Domellof L, Eriksson S, Janunger K-G. Carcinoma and possible precancerous changes of the gastric stump after Billroth II resection. Gastroenterology $1977 ; 73: 462-8$.

4 Peitsch W, Becker HD. Was ist gesichert in der Pathogenese und Häufigkeit des primären Carcinoms im operierten Magen? Chirurg $1979 ; 50: 33-8$.
${ }^{5}$ Welvaart $\mathrm{K}$, Warnsinck HM. The incidence of carcinoma of the gastric remnant. F Surg Oncol 1982;21:104-6.

${ }^{6}$ Morson BC, Soben CH, Grundmann E, Johanson A, Nagayo T, SerckHanssen A. Precancerous conditions and epithelial dysplasia in the stomach. F Clin Pathol 1980;33:711-21.

' Peitsch W, Becker HD. Frequency and prognosis of gastric stump cancer. Front Gastrointest Res 1979;5:170-7.

${ }^{*}$ Stalsberg H, Taksdal S. Stomach cancer following gastric surgery for $\mathbb{D}$

benign conditions. Lancet $1971 ;$ ii $: 1175-9$.
${ }^{y}$ Ross HAM, Smith MA, Anderson JR, Small WP. Late mortality after $气$ surgery for peptic ulcer. $N$ Engl $\mathcal{F}$ Med $1982 ; 307: 519-22$.

${ }^{10}$ Morgenstern L, Yamakawa T, Seltzer D. Carcinoma of the gastric stump. Am f Surg 1973;125:29-38.

11 Morson BC, Dawson IMP. Gastrointestinal pathology. 2nd ed. London: Blackwell Scientific, 1979:152.

12 Farrands PA, Blake JRS, Ansell ID, Cotton RE, Hardcastle JD. Endoscopic $\overline{\bar{\omega}}$ review of patients who have had gastric surgery. Br Med $\mathcal{f} 1983 ; 286:$ :
$755-8$.

13 Serck-Hanssen A. Precancerous lesions of the stomach. Scand F Gastro- @ֶ) enterol [Suppl] 1979;14:104-5.

${ }^{14}$ Morson BC. Carcinoma rising from areas of intestinal metaplasia in the $\overrightarrow{0}$ gastric mucosa. Br f Cancer 1955;9:377-85.

${ }^{15}$ Cheli $\mathrm{R}$, Simon L, Asth $\mathrm{H}$, et al. Atrophic gastritis and intestinal metaplasia $\vec{\omega}$ in asymptomatic Hungarian and Italian populations. Endoscopy 1980; O 12:105-8.

${ }^{16}$ Correa P, Cuello C, Duque E. Carcinoma and intestinal metaplasia of the stomach in Columbian migrants. FNCI 1970;44:297-306.

17 Siurala M, Varis K, Wiliasalo M. Studies of patients with atrophic $\underset{\mathcal{N}}{\mathcal{N}}$ gastritis: a 10-15 year follow-up. Scand 7 Gastroenterol 1966;1:40-8.

18 Johnston DH. Blind gastric and duodenal mucosal biopsies on patients with duodenal ulcer and those with an ulcer-like syndrome. Southern Medical fournal 1964;57:79-84.

19 Domellof L, Reddy BS, Weisburger JH. Microflora and deconjugation of bile acids in alkaline reflux after partial gastrectomy. Am 7 Surg 1980;140:291-5.

${ }^{20}$ Reed PI, Smith PLR, Haines K, House FR, Walters CL. Gastric juice $\mathrm{N}$-nitrosoamines in health and gastroduodenal disease. Lancet 1981;i: $\vec{N}$ 550-2.

${ }^{21}$ Milton-Thompson GJ, Lightfoot NF, Ahmet L, et al. Intragastric $O$ acidity, bacteria, nitrite and $\mathrm{N}$-nitroso compounds before during and $\Phi$ after cimetidine treatment. Lancet 1982 ; : 1091-5.

(Accepted 2 August 1983)

\title{
Histology of the postoperative stomach before and after diversion of bile
}

\author{
P C H WATT, J M SLOAN, ANNE SPENCER, T L KENNEDY
}

\begin{abstract}
Gastric biopsy specimens were taken in 33 patients before and after procedures to divert bile (construction of Roux loop in 19, closure of gastrojejunostomy in 14). Each biopsy specimen was assessed for dysplasia, intestinal metaplasia, atrophy, and gastritis, each variable being given a score ranging from 0 to 6 . Patients were given
\end{abstract}

Departments of Surgery and Pathology, Queen's University, Belfast P C H WATT, MB, FRCS, research fellow

J M SLOAN, MD, MRCPATH, consultant pathologist

Royal Victoria Hospital, Belfast

ANNE SPENCER, $\mathrm{MB}, \mathrm{BCH}$, research assistant

T L KENNEDY, $M C H$, FRCS, consultant surgeon

Correspondence to: Mr P C H Watt, Department of Surgery, Queen's University of Belfast, Institute of Clinical Science, Grosvenor Road, Belfast BT 12 6BJ. preoperative and postoperative scores for each of these variables based on the average score of all preoperative or postoperative specimens. Comparison between pre- 0 operative and postoperative histology showed that there $\stackrel{3}{J}$ was no difference for gastritis, atrophy, or intestinal $N$ metaplasia. Patients who underwent closure of a gastro- $\rightarrow$ jejunostomy showed improvement in dysplasia that was not statistically significant. There was, however, a $N$ significant improvement in dysplasia in patients in whom N a Roux loop was fashioned $(p=0.006)$ and in all patients $O$ taken together $(p=0.002)$.

It was concluded that procedures that divert bile $\stackrel{?}{=}$

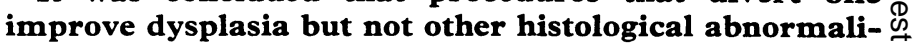
ties in the stomach postoperatively.

\section{Introduction}

Gastric mucosal dysplasia has recently given cause for concern because of its possible premalignant potential. ${ }^{12}$ After operation $\delta$ the stomach appears to be especially prone to this abnormality. ${ }^{3}$ Domellof suggested that reflux of bile into the stomach after $\frac{0}{\partial}$ 